\title{
Biocoagulation and its Application Potentials for Mineral Bioprocessing
}

\author{
Halit Z. Kuyumcu, ${ }^{1, *}$, Tina Bielig ${ }^{1}$, Annamaria Vilinska ${ }^{2}$ and K. Hanumantha Rao ${ }^{2}$ \\ ${ }^{I}$ Department of Mechanical Process Engineering \& Solids Processing, Technical University of Berlin, Sekr. BH 11, \\ Strasse des 17. Juni 135, D-10623 BERLIN, Germany, ${ }^{2}$ Division of Mineral Processing, Department of Chemical \\ Engineering \& Geosciences, Luleå University of Technology, SE-971 87 LULEÅ, Sweden
}

\begin{abstract}
Summary: The well-known sorting processes like density separation, separation in magnetic or electric fields and flotation, are not suitable to apply successfully within a particle-size range smaller than $10 \mu \mathrm{m}$. Due to insufficient selectivity of above mentioned enrichment processes the concentrate recovery at this particle size range is extremely poor, which influences accordingly the techno-economic efficiency of mineral processing negative.

Based on a process design idea, investigations confirm that the biocoagulation of microorganisms and solid particles can be used to generate coarser sized coagulates which are more suitable for sorting. Experimental investigations showed that microorganisms like Saccharomyces cerevisiae and Yarrowia lipolytica and sulphide particles like galena and sphalerite below $10 \mu \mathrm{m}$ coagulate effectively. Theoretical thermodynamic and extended DLVO theory calculations are in good agreement with microorganisms adhesion onto metal sulphides but not on silicates and selective biocoagulation of sulphides. Furthermore it has been demonstrated that flotation is suitable for the separation of the selectively formed biocoagulates.
\end{abstract}

\section{INTRODUCTION}

The technical relevant sorting processes like density, magnetic or electrical separation and flotation, require a narrow particle-size range for a sufficient selectivity in order to eliminate overlapping effects. Because of the rapid decrease of the mass forces and increase of the surface energetic state with decreasing particle size the well-known sorting processes are not applicable to an effective separation of particle sizes smaller than $10 \mu \mathrm{m}$. Moreover, the necessity of sorting processes for finely dispersed solid systems is increasing. Additionally, new sorting processes are useful in the cleaning of wastewater to remove a variety of suspended particles [1].

For obtaining a selective enrichment and recovery of sorting products in that particle size range, usually chemical dissolution or leaching processes are used. Bioleaching methods to treat copper, uranium, zinc and refractory gold ores, complex sulphides, manganese ores and industrial minerals have been developed and those processes have been adopted by the industry. The major hurdle for wider acceptance of these processes is their very slow rate of the biooxidation step of minerals. Among the several ideas on the mechanism of biooxidation, one possible explanation is that the adhesion of the bacteria on the minerals induces the oxidation process. Mechanisms and biochemical fundamentals of bacterial metal sulphide oxidation has been reported by Sand et al. [2].

*Address correspondence to this author at the Department of Mechanical Process Engineering \& Solids Processing, Technical University of Berlin, Sekr. BH 11, Strasse des 17. Juni 135, D-10623 BERLIN, Germany;

E-mail: kuyumcu@aufbereitung.tu-berlin.de
Generally, the possibilities of material separation by using microorganisms can be explained based on several microbially-mediated transformation mechanisms for dissolved metals and dispersed solid particulate materials. The mechanisms are exemplified in Table $\mathbf{1}$ and Fig. (1).

Biosorption and bioaccumulation are based on interactions of microbial cells and soluble metals and metalloids. Microbial cell surface and organelles offer a large number of active functional groups and possible physicochemical mechanisms of interaction. The result is the immobilization of the metals and metalloids on the microbial biomass. Sometimes the binding is reversible. Biosorption is defined as selective or non selective sequestering of dissolved metals by microbial cells and refers mostly to passive physicochemical mechanisms of inactive (non-metabolizing) metal uptake by microbial biomass. Various mechanisms may occur, e.g. complexation, coordination, chelation, ion exchange, adsorption, microprecipitation and reductionoxidation [3].

Bioaccumulation is referred to as active absorption (as opposed to the passive physicochemical adsorption-retention assigned to biosorption). Passive adsorption is rapid and independent of the presence of specific nutrients, whereas active absorption is slow and nutrient dependent. Bioaccumulation of metals into a cell generally requires metabolic energy, enzymatic activity and specific transport systems to move material through a cell membrane. It also depends on the tolerance of the microorganisms to the concentration of possibly toxic elements in the intracellular cytoplasm and other subcellular components but may be dependent or independent of metabolism [4]. 
Table 1. Mechanisms of Microbially-Mediated Transformations

\begin{tabular}{|l|l|l|}
\hline Biosorption & Bioaccumulation & Biocoagulation \\
\hline exocellular or pericellular binding of metals & intracellulare uptake of metals & adhesion on surface \\
\hline \hline Mechanisms: & Active Transport requires: & Thermodynamic approach \\
\hline$\bullet \quad$ Ion exchange & $\bullet \quad$ specific membrane transport systems & $\bullet$ interfacial free energy \\
\hline Complexation & & \\
\hline Chelation & $\bullet$ metabolic energy & DLVO approach \\
\hline Coordination & $\bullet$ enzymatic activity & $\bullet$ Lifshitz-van der Waals attractive forces \\
\hline$\bullet$ Adsorption-Retention & & $\bullet$ electrostatic forces \\
\hline Reduction-Oxidation & & $\bullet$ acid/base interaction forces \\
\hline
\end{tabular}

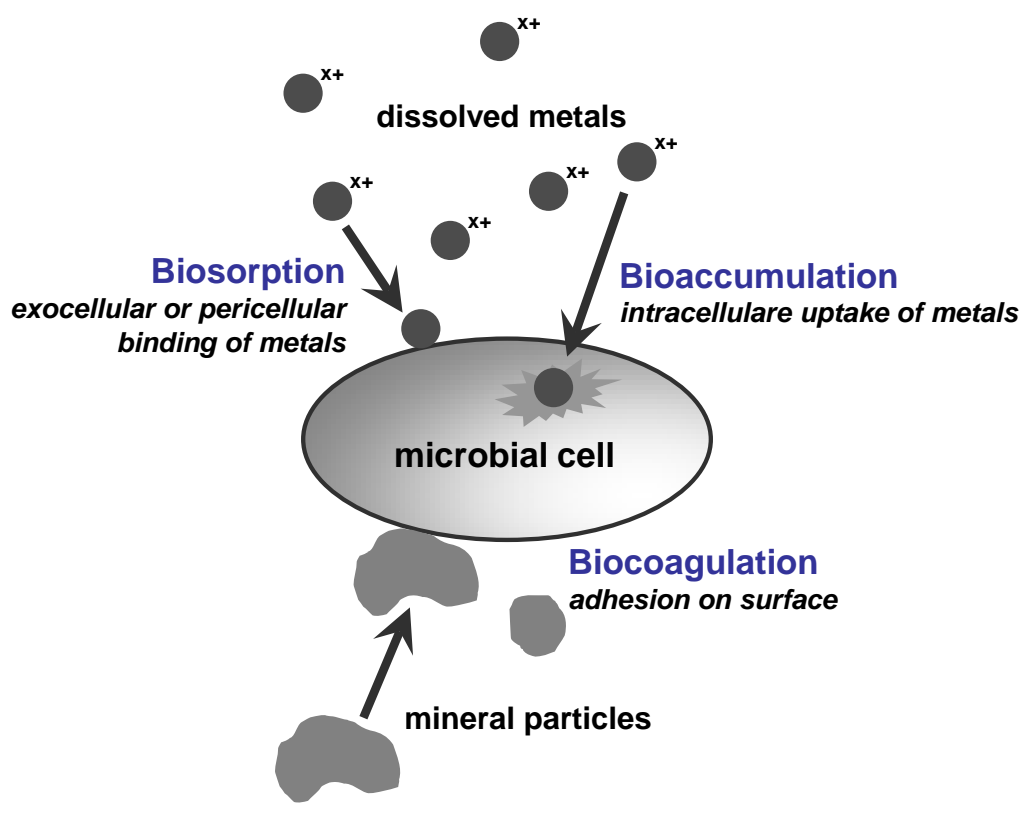

Fig. (1). Microbially-mediated transformations.

\subsection{Bacteria - Mineral Interactions}

Bacterial adhesion on mineral substrates can be assessed by surface thermodynamics and extended DLVO theory of Lifshitz-van der Waals, electrostatic and acid-base interactions [5-7]. According to thermodynamics, mineral particles and bacterial cells dispersed in a liquid medium change to an adhered system (= coagulation) if such a change leads to a lower energy state. The free energy of adhesion $\left(\Delta \mathrm{G}_{\text {adh }}\right)$ can be expressed by

$$
\Delta G_{a d h}=\gamma_{b s}-\gamma_{b l}-\gamma_{s l}
$$

where $\gamma$ represents interfacial free energies for bacteriasolid (bs), bacteria-liquid (bl) and solid-liquid (sl) [5].

For the calculation of the free energy of adhesion $\left(\Delta \mathrm{G}_{\mathrm{adh}}\right)$, the Lifshitz-van der Waals component (LW) and the acid-base component (AB) have to be considered:

$$
\Delta G_{a d h}=\Delta G_{a d h}^{L W}+\Delta G_{a d h}^{A B} .
$$

Calculation according to $\mathrm{LW}-\mathrm{AB}$ approach using the Lifshitz-van der Waals dispersive and acid-base components of surface energies is:

$$
\Delta G_{a d h}^{L W}=-2\left(\sqrt{\gamma_{b v}^{L W}}-\sqrt{\gamma_{l v}^{L W}}\right)\left(\sqrt{\gamma_{s v}^{L W}}-\sqrt{\gamma_{l v}^{L W}}\right)
$$

and

$$
\begin{aligned}
& \Delta G_{a d h}^{A B}=2\left(\sqrt{\gamma_{b v}^{+}}-\sqrt{\gamma_{s v}^{+}}\right)\left(\sqrt{\gamma_{b v}^{-}}-\sqrt{\gamma_{s v}^{-}}\right)-2\left(\sqrt{\gamma_{b v}^{+}}-\sqrt{\gamma_{v v}^{+}}\right)\left(\sqrt{\gamma_{b v}^{-}}-\sqrt{\gamma_{v v}^{-}}\right) \\
& -2\left(\sqrt{\gamma_{s v}^{+}}-\sqrt{\gamma_{l v}^{+}}\right)\left(\sqrt{\gamma_{s v}^{-}}-\sqrt{\gamma_{l v}^{-}}\right)
\end{aligned}
$$

Classical DLVO approach [8, 9] includes Lifshitz-van der Waals (LW) interactions, and electrostatic interactions. LW forces are always attractive and strong at shorter distances between neutral stable molecules. Coulombic electrostatic interaction forces could be attractive or repulsive depending on the surface charge of interacting particles. 


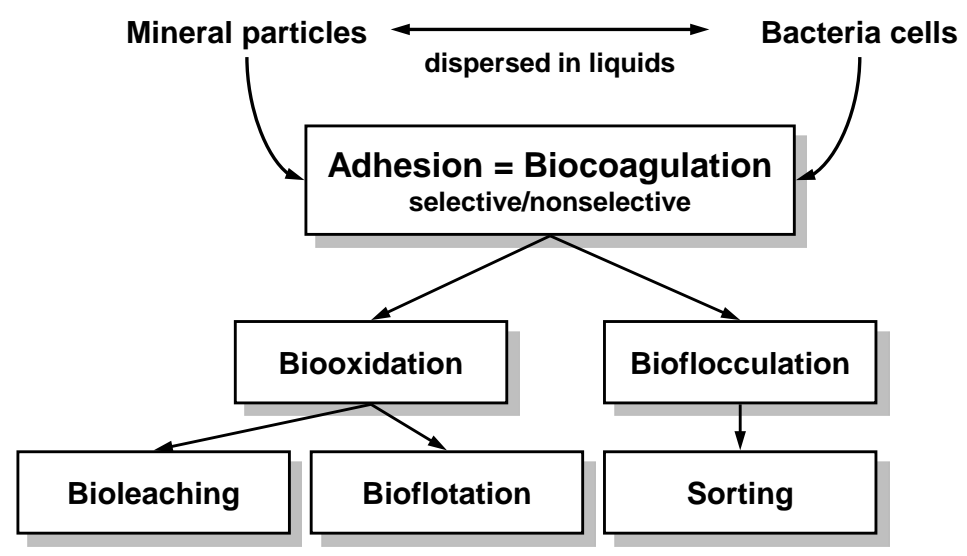

Fig. (2). Mineral Bioprocessing of dispersed systems based on biocoagulation.

Acid-base interactions were added later by van Oss [10] to involve the electron donating-accepting abilities of different materials. Thus microbial adhesion to solid surfaces can be described by a sum of van der Waals, electrostatic and acid-base forces as a function of separation distance

$\mathrm{G}^{\text {total }}=\mathrm{G}^{\mathrm{LW}}+\mathrm{G}^{\mathrm{EL}}+\mathrm{G}^{\mathrm{AB}}$.

Calculation of these forces depends on the geometry of interacting phases and for sphere-sphere system, the following equations were used:

Lifshitz-van der Waals interaction energy:

$$
\begin{aligned}
& G^{L W}=-\frac{A}{12}\left[\frac{y}{x^{2}+x y+x}+\frac{y}{x^{2}+x y+x+y}+2 \ln \left(\frac{x^{2}+x y+x}{x^{2}+x y+x+y}\right)\right] \\
& \left(\frac{1}{1+1.77\left(\frac{2 \pi H}{\lambda}\right)}\right)
\end{aligned}
$$

Electrostatic interaction energy:

$G^{E L}=\frac{\pi \varepsilon a_{1} a_{2}\left(\zeta_{1}+\zeta_{2}\right)}{a_{1}+a_{2}}\left[\frac{2 \zeta_{1} \zeta_{2}}{\zeta_{1}+\zeta_{2}} \ln \frac{1+e^{-\kappa H}}{1-e^{-\kappa H}}+\ln \left(1-e^{-2 \kappa H}\right)\right]$

Acid-base interaction energy:

$\mathrm{G}^{\mathrm{AB}}=\pi \mathrm{a} \lambda \Delta \mathrm{G}_{\mathrm{adh}}{ }^{\mathrm{AB}} \mathrm{e}^{\left[\left(\mathrm{d}_{\mathrm{o}}-\mathrm{H}\right) / \lambda\right]}$

where $\mathrm{H}$ - separation distance, a - radius of solid particle, $\zeta$ - zeta-potential, $\kappa$ - inverse of double layer thickness, A - Hamaker constant, $\mathrm{d}_{0}$ - minimum separation distance between 2 surfaces $(0.157 \mathrm{~nm}), \lambda$ - correlation length of molecules in liquid $(0.6 \mathrm{~nm})$ and $x=H /\left(a_{1}+a_{2}\right), y=a_{1} / a_{2}$

For interaction energy calculation, the parameters such as zeta-potential, particle radius, double layer thickness are known or measurable, while for calculation of Hamaker constant there are two different methods available. The Hamaker constant value that influences the Lifshitz-van der Waals interaction energy could be obtained by microscopic and macroscopic approaches [11, 12], but according to our previous studies [13] the macroscopic approach was found to be more relevant. Macroscopic method [12] determines the Hamaker constant using the Lifshitz-van der Waals component of free energy of adhesion $\Delta G_{a d h}{ }^{L W}$ :
$\mathrm{A}=-12 \pi \mathrm{d}_{0}^{2} \Delta \mathrm{G}_{\mathrm{adh}}{ }^{\mathrm{LW}}$.

\subsection{Bio-separation Processes}

Based on bacterial adhesion mechanism, several separation processes can be achieved and potentially used for bioprocessing, if the process can be performed selectively, refer to $[14,15]$. The most interesting technological potentials of the mineral bioprocessing of dispersed systems are shown in Fig. (2).

Several approaches to separate solid particles with microbes were investigated in the last decades. The possibility of using bacteria and fungi as flocculants for Florida phosphatic clays was investigated early in 1963 [16]. Flocculation of phosphate slimes, hematite and coal by using Mycobacterium phlei was tested in 1991 [17]. Mycobacterium phlei produce extracellular polymers and surfactants under certain conditions, which can cause flocculation of the microorganisms themselves or of other solids, as exemplarily reported by Long et al. [18]. Several studies have shown the potential of microorganisms to be used as flotation collectors or modifiers. The depression of pyrite in coal flotation has been reported by Capes et al. [19]. The selective separation of sphalerite from pyrite has been studied in the presence of Acidobacillus ferrooxidans [20]. The surface energies of 140 bacterial and seven yeast cell surfaces following Fowkes, Equation of state and Geometric mean and Lifshitz-van der Waals acid-base (LW-AB) approaches have been extensively studied and evaluated by Rao et al. [21].

The design idea to realize a biocoagulation based sorting process is composed of three main steps (Fig. 3):

1. the selective biocoagulation of microorganisms and finesized mineral particles,

2. the separation of the biocoagulates out of the slurry and

3. the detachment of microorganisms and particles, aiming to recover and recycle the biomass (optional).

\section{MATERIALS AND METHODS}

\subsection{Materials}

Preliminary tests were carried out with different solid particles and microorganisms. The results presented here are based on the use of the sulphide minerals galena $(\mathrm{PbS})$ and sphalerite $(\mathrm{ZnS})$. The basic modules of both mineral structures are ions. Both lattices belong to the AB-lattice-type. 


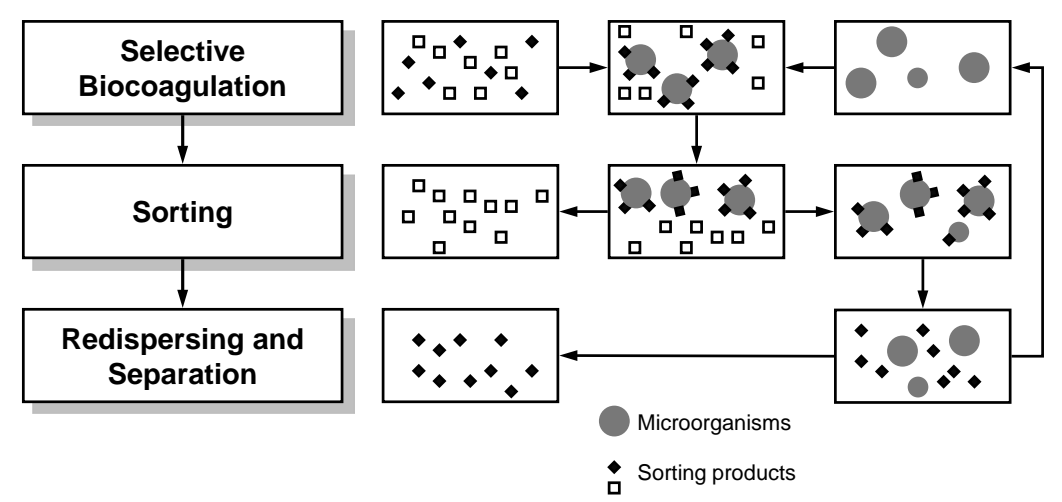

Fig. (3). Assumed process design.

Pure minerals were used as test materials. First of all the minerals were crushed and milled. Afterwards the fraction $<10 \mu \mathrm{m}$ was separated to be used in the tests.

After some preliminary trials two different yeast cultures, Yarrowia lipolytica and Saccharomyces cerevisiae were selected as microorganisms. For them growth curves were determined. The optimal conditions for the coagulation tests were achieved in the middle of the exponential growth phase, when $10^{8}$ cells per millilitre medium were counted. At that point of time, the yeasts were harvested.

The following growing media were used:

- Sabouraud-Glucose-Broth(SGB)-medium for Saccharomyces cerevisiae. The medium consisted of peptones of meat and milk proteins (casein, nitrogen and carbon source) and glucose (energy source, $2 \%$ ). The $\mathrm{pH}$-value of the used medium was $5.7 \pm 0.2$.

- Yeast-Extract-Peptone-Glucose(YEP)-medium for Yarrowia lipolytica. The medium consisted of a mixture of $1 \%$ yeast-extract, $2 \%$ peptone from casein and $2 \%$ glucose.

\subsection{Contact Angle Measurements}

The contact angles on yeast cells and mineral powders were obtained by sessile drop method and sorption measurements respectively. For the sessile drop method was used for the yeast cells, a uniform thick layer of cells were created by filtration through a Millipore filter paper. The filter paper was then fixed on a glass slide with the help of double sided tape. The samples were air-dried to remove the rest of water moisture and contact angles were measured while placing a drop of liquid on the bacterial lawn surface. The dynamic contact angle was recorded with Krüss Easy drop equipment and evaluated with Drop Shape analysis software. A drop of liquid is placed on a bacterial lawn flat surface with the help of a syringe and advancing angle is recorded on a CCD camera. Each measurement was repeated 3 times and the arithmetic mean was considered as the final contact angle for a particular liquid.

Contact angle on solid powders was determined by sorption measurements using Krüss Tensiometer K100 and Krüss LabDesk 3.1 software. The Washburn equation is used to measure the contact angle on powder samples. When a column of powder bed is in contact with liquid, the pores between the particles act like small capillaries and the rise of liquid is measurable. The capillary constant in Washburn equation was determined using n-Hexane (low energy wetting liquid) that wets the solids completely. Using the obtained capillary constant, the contact angles for other liquids were determined.

Mineral samples of $-106+38 \mu \mathrm{m}$ size fraction were used. A $1 \mathrm{~g}$ of mineral was placed into a glass sample tube and was carefully and equally packed each time. Each measurement was repeated at least 3 times and the results found to be reproducible within \pm 3 degrees deviation and a mean value was reported in the results.

For the estimation of acid and base surface energy components by van Oss method, contact angles of at least three different test liquids with well characterized acid and base components are necessary. Three standard liquids of water, 1-bromonaphtalene and formamide were used. The values of liquids surface tension and the dispersive and polar part contributions to the surface energy, and the polar part divided into acid and base components of surface energy as reported in the literature were used [22, 23].

\subsection{EPS Analysis}

The essential groups of eukaryotic cell walls are the hydroxyl-, carbonyl-, carboxyl-, amino- and phosphate groups. In dependency on the environmental conditions, these groups have an influence on the electrochemical charge of the cell wall [24, 25]. Additionally the microbes produce extracellular polymeric substances (EPS) that may have an influence on the environmental conditions. They are mostly composed of polysaccharides, proteins, nucleic acids and lipids.

At "Biofilm Centre" of University of Duisburg-Essen the extracellular polymeric substances (EPS) of the yeasts Saccharomyces cerevisiae and Yarrowia lipolytica were analysed. The results are summarized in Table 2 . It was found that the EPS composition of both yeasts is very similar. Both of the yeast cultures are enabling selective biocoagulation of the tested minerals.

\subsection{Zeta-Potential Analysis}

Microscopic investigations and zeta-potential analysis were done immediately after adjustment of the defined condition ( $\mathrm{pH}$-value, electrical conductivity) for the yeasts and the prepared minerals. For those purposes a light-scattering microscope (Jenoptik) and a Malvern zeta-sizer were used.

The Malvern zeta-sizer "Nano Z" uses a combination of electrophoresis and Laser Doppler Velocimetry to determine 
Table 2. EPS of the Yeasts Saccharomyces Cerevisiae and Yarrowia Lipolytica

\begin{tabular}{|c|c|c|}
\hline & Yarrowia Lipolytica & Saccharomyces Cerevisiae \\
\hline \hline EPS & $1000 \mathrm{mg}$ & $1000 \mathrm{mg}$ \\
\hline Carbohydrates & $898 \pm 26 \mathrm{mg}$ & $803 \pm 66 \mathrm{mg}$ \\
\hline Proteins & $82 \pm 11 \mathrm{mg}$ & $56 \pm 9 \mathrm{mg}$ \\
\hline Uronic acid & $4.2 \pm 1.1 \mathrm{mg}$ & $4.6 \pm 1.0 \mathrm{mg}$ \\
\hline
\end{tabular}

the zeta-potential. The principle is the measurement of the particle velocity in a liquid of known ionic strength when applying an electrical field. The relation between velocity and electrical strength is called electrophoretic mobility and can be used to calculate the zeta-potential. The zeta-potential of the single minerals, yeasts as well as the zeta-potential of the biocoagulates at a given $\mathrm{pH}$-value are obtained from the maximum value of the measured values distribution from several tests. Fig. (4) shows an example of a zeta-potential measurement for Yarrowia lipolytica at a $\mathrm{pH}$-value of 2 .

Hence, zeta-potential measurements of the single yeasts and biocoagulates at different $\mathrm{pH}$-values were made in addition to measurements of the single sulphide minerals. The isoelectric point of each material used could be determined. Fig. (5) shows the results with Yarrowia lipolytica and galena and sphalerite respectively [26].

\subsection{Thermodynamic Analysis of Cell Adhesion}

The contact angle of test liquids on different surfaces and their surface energies are presented in Table 3. For Yarrowia lipolytica yeast cells, the surface energy values that reported by Aguedo et al. [27] are shown. Sulphide minerals comprise considerably higher dispersive component of surface energy than quartz. The polar component of sulphide surfaces is much lower compared to quartz. The electron donating property of minerals is in the order of quartz > sphalerite > galena, which is understandable since quartz surface mostly contain silanol groups. Quartz has a well balanced surface, with almost equal dispersive and polar components of surface energy. Saccharomyces Cerevisiae cells surface has higher dispersive component of surface energy than Yarrowia Lipolytica cells but reverse is the polar component. All the studied surfaces have a dominant electron donating part. Saccharomyces cerevisiae cells expected to be hydrophilic due to their higher water-wetting abilities, but a low contact angle with a non-polar liquid display the nonpolar character of their surfaces. A significant portion of the surface energy attributes to the polar part where the electron donating part is prominent. The non-polar and polar parts of Yarrowia lipolytica surfaces are more balanced with more

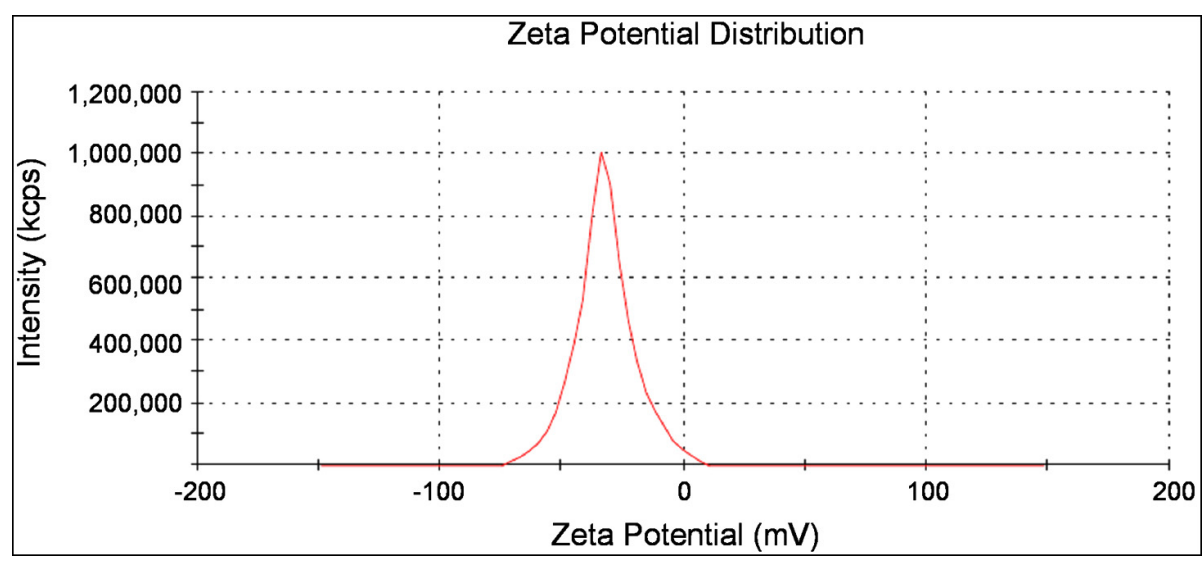

Fig. (4). Zeta-potential of Yarrowia lipolytica at $\mathrm{pH} 2$ in 0.03 mol potassium chloride.
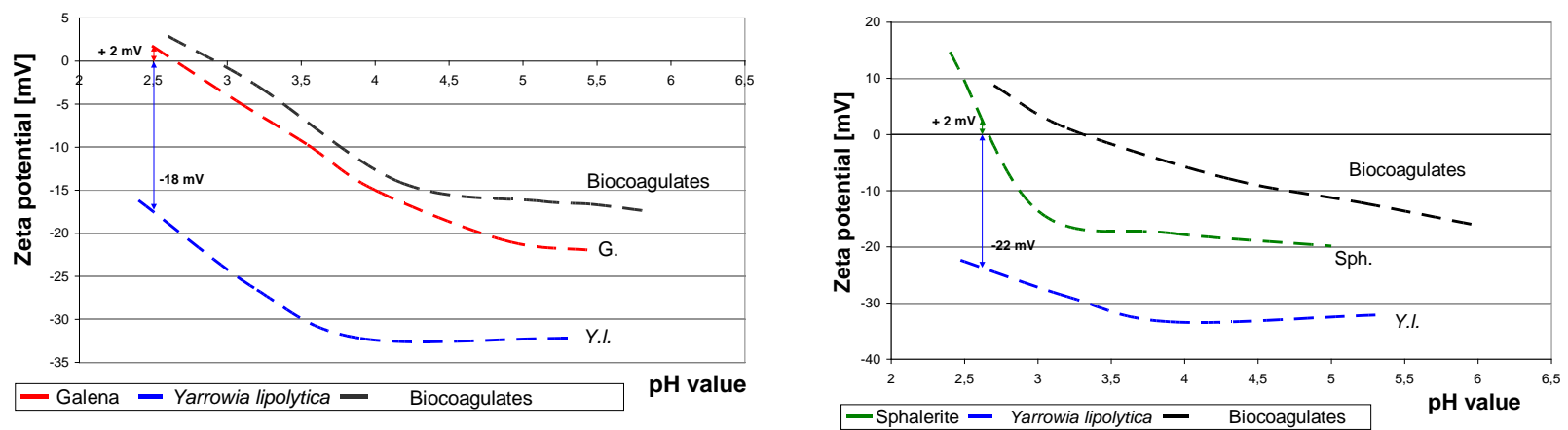

Fig. (5). Zeta-potential of Yarrowia lipolytica, the minerals and biocoagulates. 
Table 3. Contact Angle Data and Surface Energy Values Determined by Acid-Base Approach

\begin{tabular}{|c|c|c|c|c|c|c|c|c|}
\hline \multirow[b]{2}{*}{ Material } & \multicolumn{3}{|c|}{ Contact Angle $\theta$} & \multicolumn{5}{|c|}{ Surface Energy $\gamma\left(\mathbf{m J} . \mathbf{m}^{-2}\right)$} \\
\hline & Water & Bromo-Naphtalene & Forma-Mide & Total & $\gamma^{\mathrm{d}} / \gamma^{\mathrm{LW}}$ & $\gamma^{\mathrm{P}} / \gamma^{\mathrm{AB}}$ & $\gamma^{+}$ & $\gamma^{-}$ \\
\hline Sphalerite & 68.70 & 30.88 & 53.40 & 40.64 & 38.50 & 2.13 & 0.08 & 14.51 \\
\hline Y. Lipolytica & & & & 56.20 & 23.60 & 32.60 & 8.00 & 33.40 \\
\hline
\end{tabular}

dominating polar part. The strong electron donating character of the microorganisms can be explained by the predominance of polysaccharide compounds and extra-cellular polymeric substances (EPS) rich in -OH groups on the cells surface.

Free energy of adhesion computed by LW-AB approach for different mineral-yeast cells are presented in Table 4. The Lifshitz-van der Waals free energy component is negative for all the systems studied where the systems with Yarrowia lipolytica exhibited less negative. The acid-base free energy component is negative only for the systems with galena and positive for sphalerite and quartz systems. The total free energy of adhesion is negative and adhesion is favourable for the systems Saccharomyces cervisiae-galena, Saccharomyces cerevisiae-sphalerite and Yarrowia lipolytica-galena. For Yarrowia lipolytica-sphalerite system, the total free energy is slightly positive foreseeing a problematic adhesion, but the free energies of adhesion are highly positive for the cell-quartz systems leading to an unfavourable adhesion. The likelihood of adhesion follows in the order of galena $>$ sphalerite $>$ quartz. This order is evidently due to the decreasing nonpolar character and increasing electron donor capabilities of the minerals in the same direction. These calculations are based on the fact that the particles and cells are dispersed in water and the mineral-cell adhesion/ coagulation leads to a lower energy system. The highly hydrophilic Yarrowia lipolytica cannot drive to leave water environment to adhere on a hydrophobic surface and the free energies of adhesion are less negative compared to Saccharomyces cerevisiae.

\subsection{Extended DLVO Analysis of Cell Adhesion}

The sphere-sphere geometry of particles for calculating the interaction forces is more suitable for mineralmicroorganism system, although the shape of particles and cells is not exactly spherical. Considering the size of interacting bodies, the spherical model is reasonable. The energy is expressed in kT units in the potential energy diagrams between the cells and minerals presented in Figs. (6 and 7). A model system was chosen for calculations with the following parameters: $\mathrm{pH} 2.5,0.01 \mathrm{M}$ electrolyte concentration and $1 \mu \mathrm{m}$ size for particles and cells. These conditions were observed to be the optimum parameters in coagulation experiments and flotation tests presented in later sections. The Hamaker constants and zeta-potentials used in the calculations are presented in Tables $\mathbf{4}$ and $\mathbf{5}$ respectively.

Table 5. Zeta-Potential Values for Different Particles at pH 2.5

\begin{tabular}{|c|c|}
\hline Material & Zeta-Potential $(\mathbf{m V})$ \\
\hline \hline Galena & 2 \\
\hline Sphalerite & 2 \\
\hline Quartz & -5 \\
\hline S. Cerevisiae & $-4,5$ \\
\hline Y. Lipolytica & -18 \\
\hline
\end{tabular}

Table 4. Free Energy of Adhesion and Calculated Hamaker Constants

\begin{tabular}{|c|c|c|c|c|}
\hline \multirow[t]{2}{*}{ Bacteria-Mineral System } & \multicolumn{3}{|c|}{ Free Energy of Adhesion $\Delta G_{\text {adh }}\left(\mathbf{m J} \cdot \mathrm{m}^{-2}\right)$} & \multirow[t]{2}{*}{ Hamaker Constant $\left(10^{-21} \mathrm{~J}\right)$} \\
\hline & $\Delta \mathbf{G}_{\text {adh }}{ }^{L W}$ & $\Delta \mathbf{G}_{\text {adh }}{ }^{A B}$ & $\Delta \mathbf{G}_{\text {adh }}{ }^{\text {total }}$ & \\
\hline S. Cerevisiae - Galena & -7.33 & -6.49 & -13.81 & 6.81 \\
\hline S. Cerevisiae - Sphalerite & -5.61 & 2.92 & -2.69 & 5.22 \\
\hline S. Cerevisiae - Quartz & -2.68 & 9.32 & 6.64 & 2.49 \\
\hline Y. Lipolytica - Galena & -0.76 & -3.38 & -4.14 & 0.70 \\
\hline Y. Lipolytica-Sphalerite & -0.58 & 1.44 & 0.86 & 0.54 \\
\hline Y. Lipolytica-Quartz & -0.28 & 4.76 & 10.98 & 0.26 \\
\hline
\end{tabular}


The interaction energy versus separation distance curves between Saccharomyces cerevisiae and minerals are shown in Fig. (6). For galena-cell system, the different interacting forces are negative resulting in a total adhesive force. The electrostatic force is rather weak while the LW forces are relatively significant. The acid-base forces are the strongest and attractive controlling the total interaction force for this system. Below the separation distance of $25 \mathrm{~A}$ the forces are attractive resulting in an adhesion. In the case of sphalerite, the electrostatic and LW forces are negative while the acid-base forces are positive creating an energetic barrier. Electrostatic forces are very weak while the LW forces are weaker compared to galena and adhesion is possible after overcoming the energetic barrier. The LW forces are attractive but the electrostatic and acid-base forces are repulsive for quartz-cell system. The strong acid-base repulsive interactions are responsible for the inability of cells adhesion on quartz.
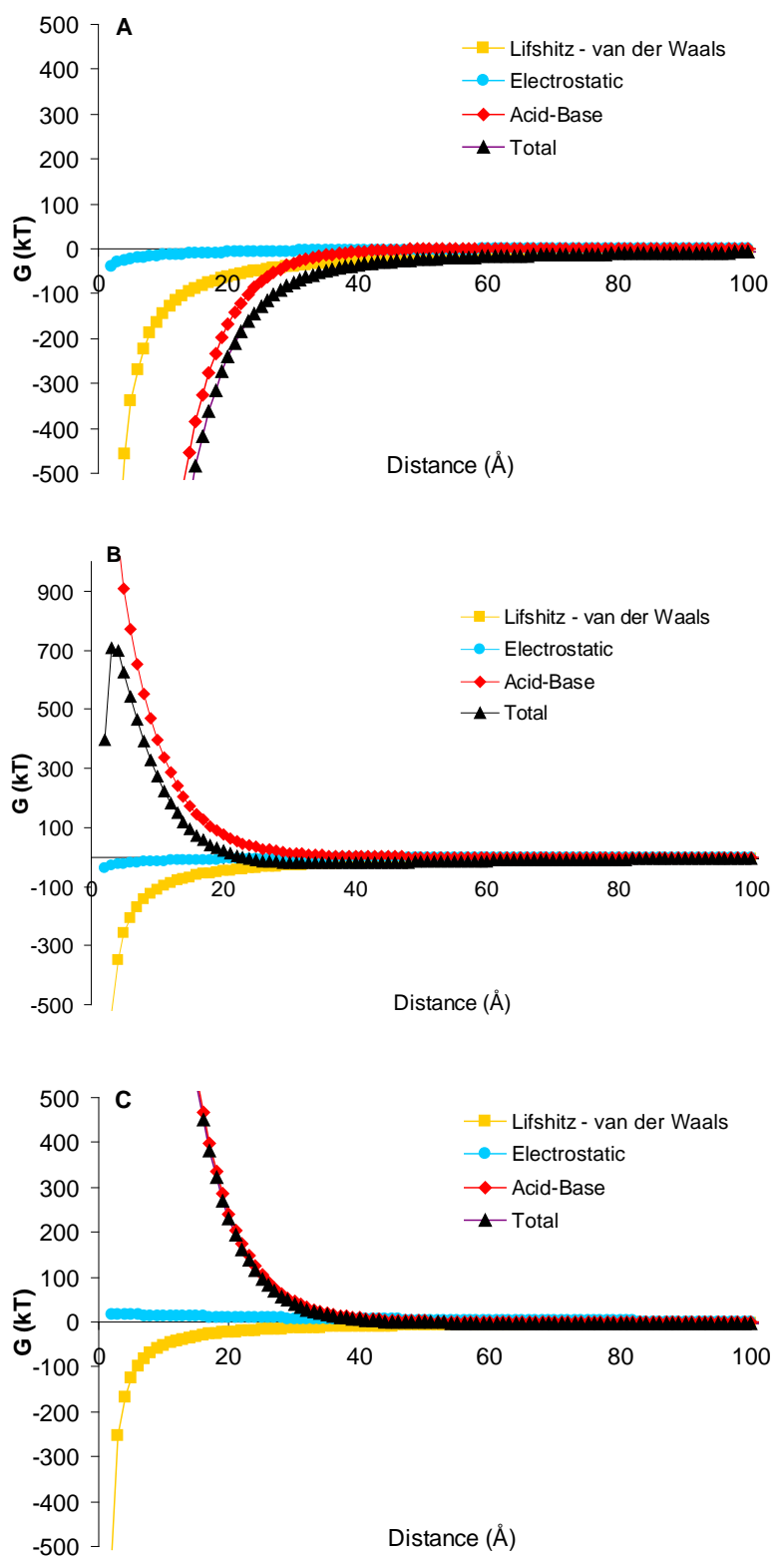

Fig. (6). Saccharomyces cerevisiae - galena (A), sphalerite (B), quartz $(\mathbf{C})$ interaction energy diagrams.
Fig. (7) shows the interaction energy curves between Yarrowia lipolytica cells and minerals versus separation distance. The LW part of free energy of adhesion for Yarrowia lipolytica-mineral systems is weaker compared to Saccharomyces cerevisiae cells adhesion and the energy curves indeed display very weak LW forces for all Yarrowia lipolytica systems. In the case of galena, the electrostatic forces are stronger and attractive due to a higher and opposing zeta-potential of Yarrowia lipolytica cells and galena. The acid-base interactions are also attractive leading to attractive total interaction energy and the cells adhesion forces towards galena are significant. Although the electrostatic forces are attractive and stronger for Yarrowia lipolytica-sphalerite system, the repulsive acid-base interactions created an energy barrier of $300 \mathrm{kT}$ which needs to overcome for adhesion to occur. Very strong acid-base repulsive forces between Yarrowia lipolytica cells and quartz render their coagulation impracticable (Fig. 7C).
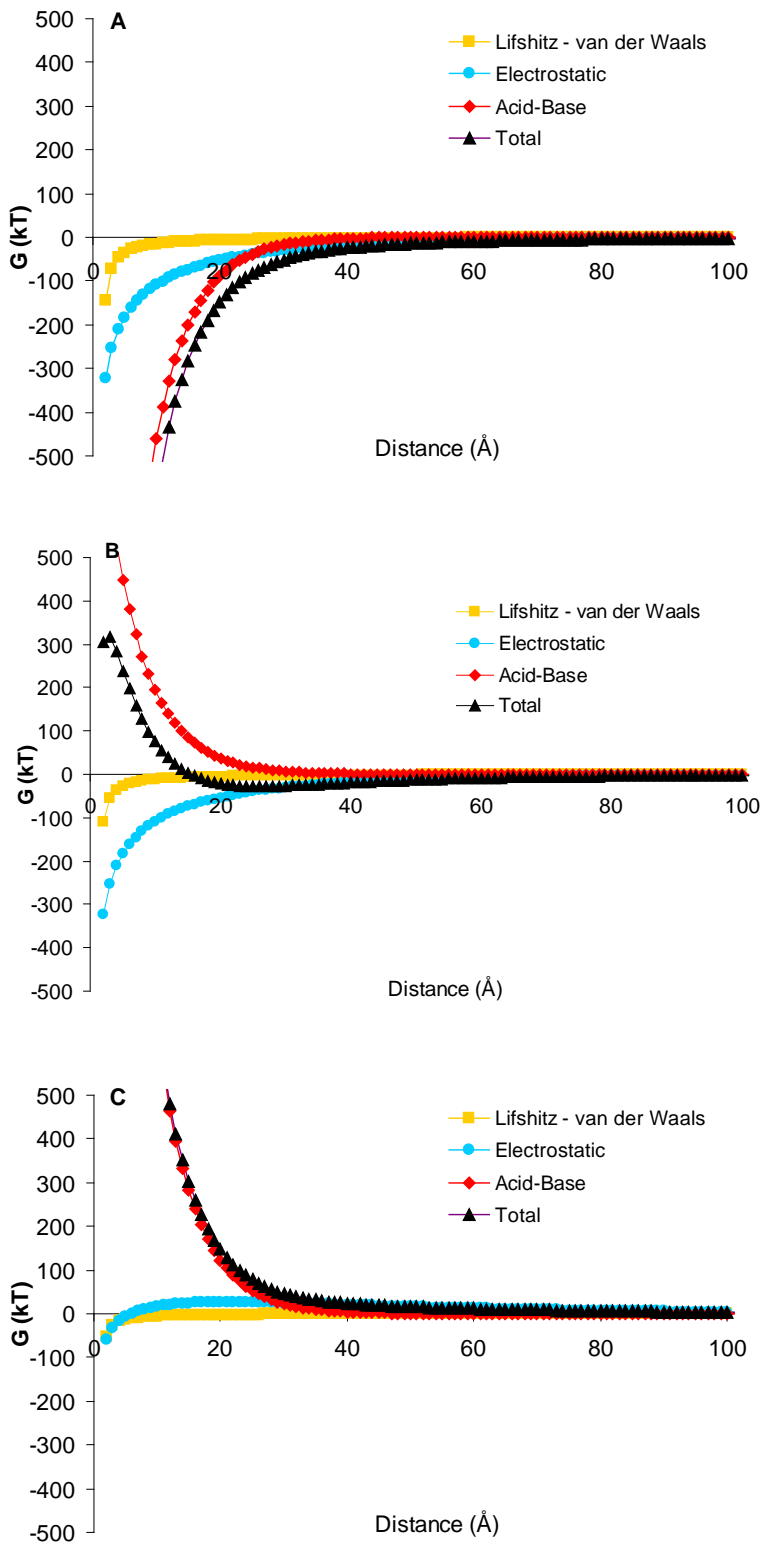

Fig. (7). Yarrowia lipolytica - galena (A), sphalerite (B), quartz (C) interaction energy diagrams. 


\section{BIOCOAGULATION TESTS}

The above in detail explained characteristics of the cell walls and the mineral surfaces allow the coagulation between the yeasts and the sulphide minerals, which was validated by microscopic pictures (Figs. 8 and $\mathbf{9}$ ). A large sized floc formation also was observed by using both of the yeast cultures.

Fig. (9) shows pictures of single biocoagulates taken by means of an atomic force microscope (AFM) applied in the "Biofilm Centre" of University of Duisburg-Essen.
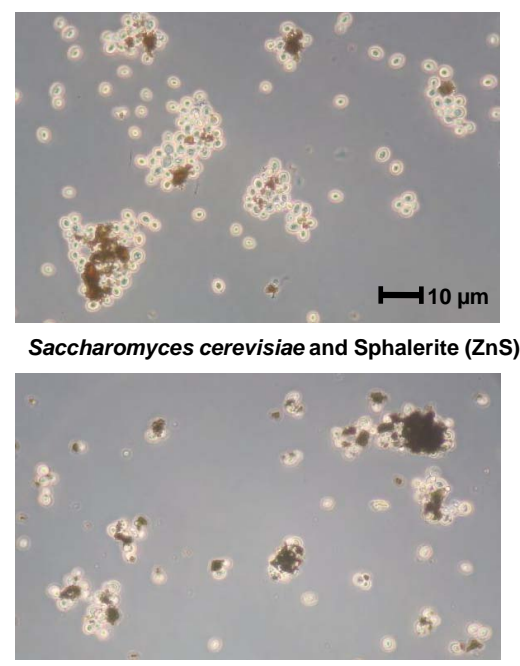

Saccharomyces cerevisiae and Galena (PbS)

Fig. (8). Microscopic pictures of the biocoagulates.
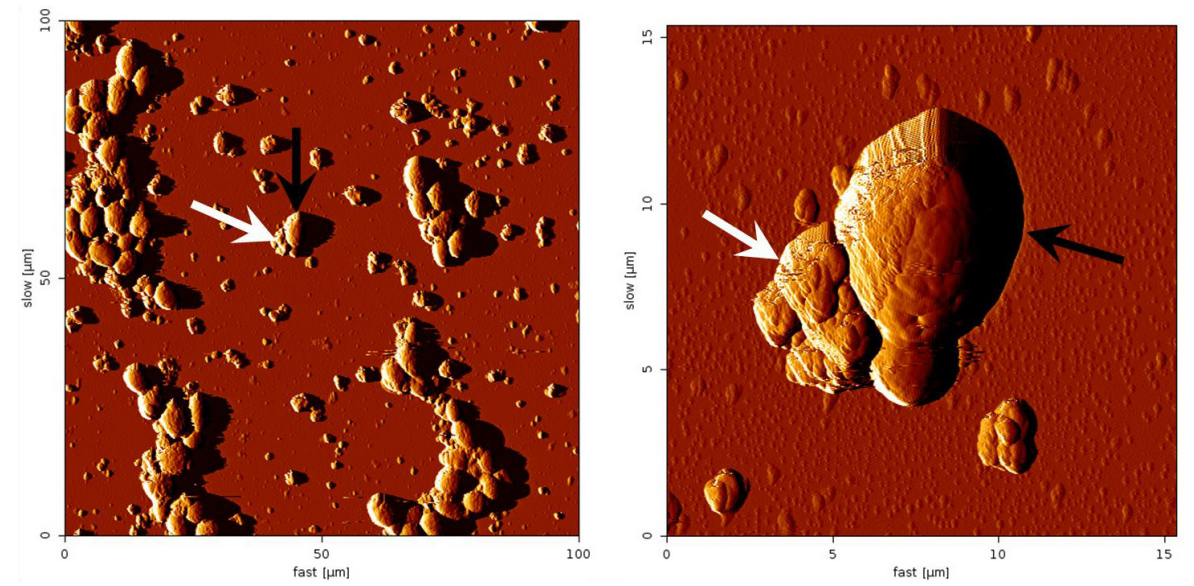

Fig. (9). AFM of Saccharomyces cerevisiae (black arrow) and Sphalerite (white arrow)

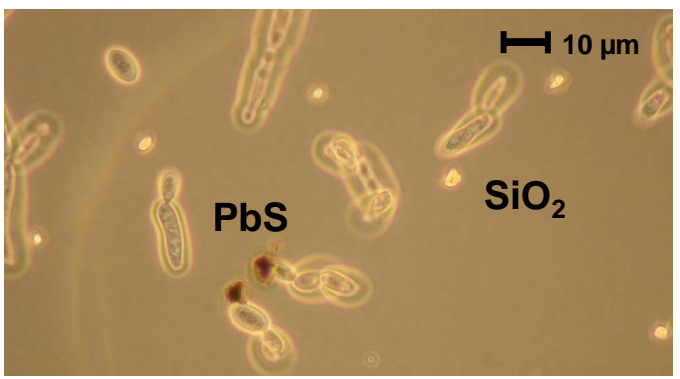

Yarrowia lipolytica and Galena, Quartz
The microscopic analyses show differences between both yeasts. The examinations with sphalerite demonstrate that Saccharomyces cerevisiae adhere at first to larger particles, whereas smaller ones are attached later on. Afterwards large coagulates and flocks are formed. For Yarrowia lipolytica it was observed, that stress during the coagulation process leads to the formation of hyphae. The optimum results of coagulation were observed in an acidic environment at about $\mathrm{pH} 2$. Tests with two binary mixtures sphalerite/quartz and galena/quartz demonstrated the selectivity of the coagulation process (Fig. 10) and corroborate the observations [14]. Galena was chosen for the further investigations.

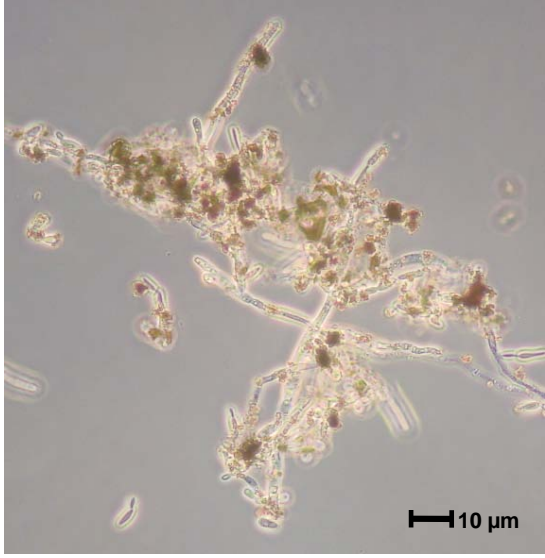

Yarrowia lipolytica and Sphalerite (ZnS)

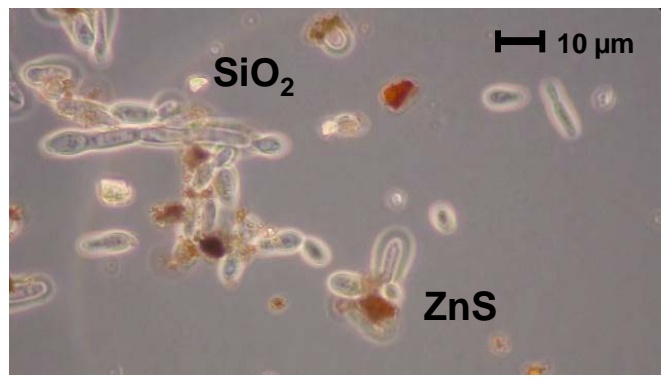

Yarrowia lipolytica and Sphalerite, Quartz

Fig. (10). Selective biocoagulation 


\section{FLOTATION TESTS}

Flotation was found to be a suitable process for the separation of microorganisms. Depending on the type of microorganisms an attachment between air bubbles and biocoagulates can be expected through natural hydrophoby of microorganisms and biocoagulates without adding any surfactants.

For sorting the biocoagulates column flotation has been used. Column flotation is especially suited to sort the very small biocoagulates, considering low shearing forces between the sulphides and the microorganisms. For the flotation tests a lab-scale flotation column was built and used for batch tests as well as for continuous flotation tests. The experimental setup is shown in Fig. (11).

The experimental work was carried out as follows:

1. Breeding of the test yeast in an external fermenter,

2. Conditioning of the yeast-mineral-suspension to form biocoagulates,

3. Feeding the suspension into the flotation (batch-wise / continuous),

4. Flotation by generating air bubbles without adding surfactants,

5. Sampling of the concentrate in time intervals,

6. Analyses of the concentrates and tailings,

7. Interpretation of the results.

The results of the flotation tests show that the designed column flotation, depending on the operating conditions, can lead to a recovery in the concentrates of more than $90 \%$ without using any additional chemicals, e.g. collectors. Without additional chemicals a pH-value of 5 was reached. Fig. (12) exemplary shows under these conditions with a constant solids concentration of $\mathrm{PbS}$ and a process time of 60 minutes a PbS-recovery of $96 \%$ with Saccharomyces cerevisiae and of $78 \%$ with Yarrowia lipolytica. Thus further tests were carried out with Saccharomyces cerevisiae.

In batch tests the influence of different process parameters on the flotation results, i.e. the recovery of mineral concentrate, was investigated. Fig. (13) exemplary shows the cumulative recovery of mineral concentrate and the flotation velocity $(\Delta \mathrm{R} / \Delta \mathrm{t})$ under variation of the $\mathrm{pH}$-value and the ratio of mineral mass to cell concentration in the pulp.

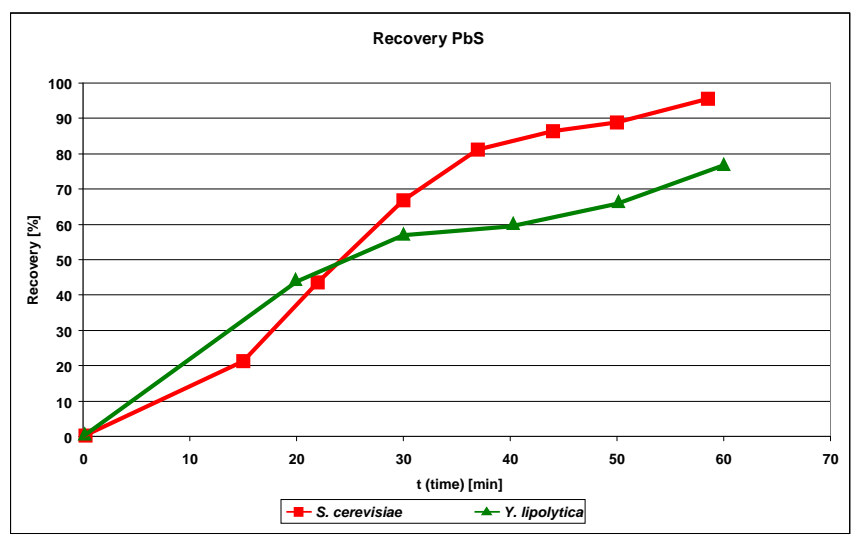

Fig. (12). Cumulative recovery of $\mathrm{PbS}$ with both yeasts, $\mathrm{pH}$ value: 5 .

Basically a pH-value of 2 is more suitable for the flotation of the biocoagulates. The flotation results at a $\mathrm{pH}$ value of 5 show no significant decline of the recovery of mineral concentrate (Fig. 13). Due to the advantages regarding the process conditions the continuous flotation tests were carried out at a higher $\mathrm{pH}$-value of 5 .

Fig. (14) exemplary shows the cumulative recovery of mineral concentrate by variation of the mineral mass to cell concentration ratio in the pulp by continuous flotation. The $\mathrm{PbS}$-recovery can reach up to $94 \%$ depending on this ratio. The higher the ratio of mineral mass to cell concentration the higher is the flotation velocity $(\Delta R / \Delta t)$ as seen in Fig. (14). The maximum value of the velocity was found to be after approximately 25 minutes [28].

\section{CONCLUSIONS}

Microbial adhesion on mineral substrates can be assessed by surface thermodynamics and extended DLVO theory of Lifshitz-van der Waals, electrostatic and acid-base interactions. According to thermodynamics, mineral particles and microbial cells dispersed in a liquid medium shift to an adhered particle system if this coagulation leads to a lower energy state. For interaction energy calculation, the parame-

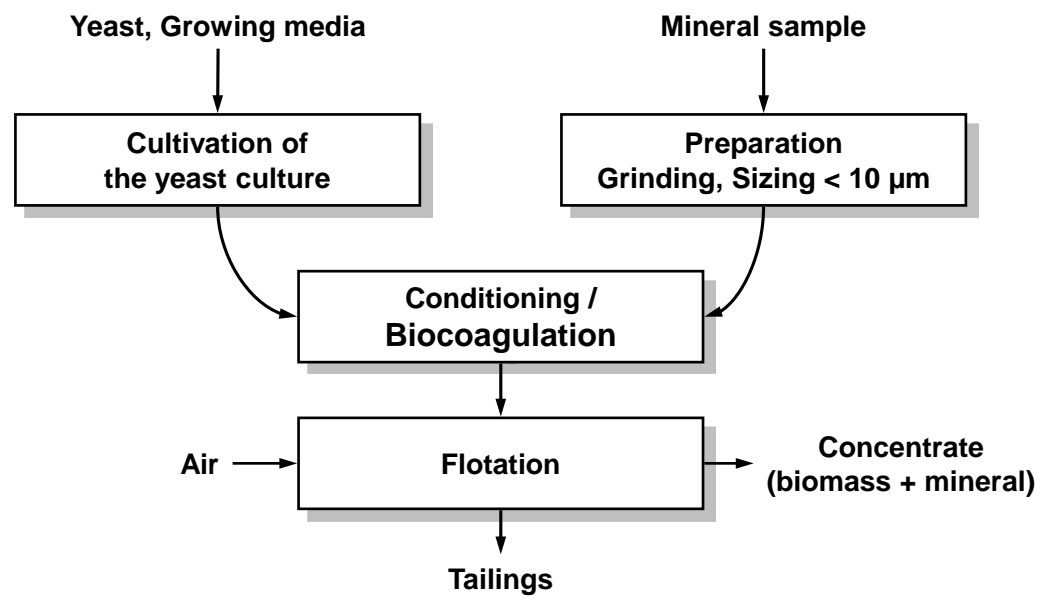

Fig. (11). Experimental setup of the flotation. 

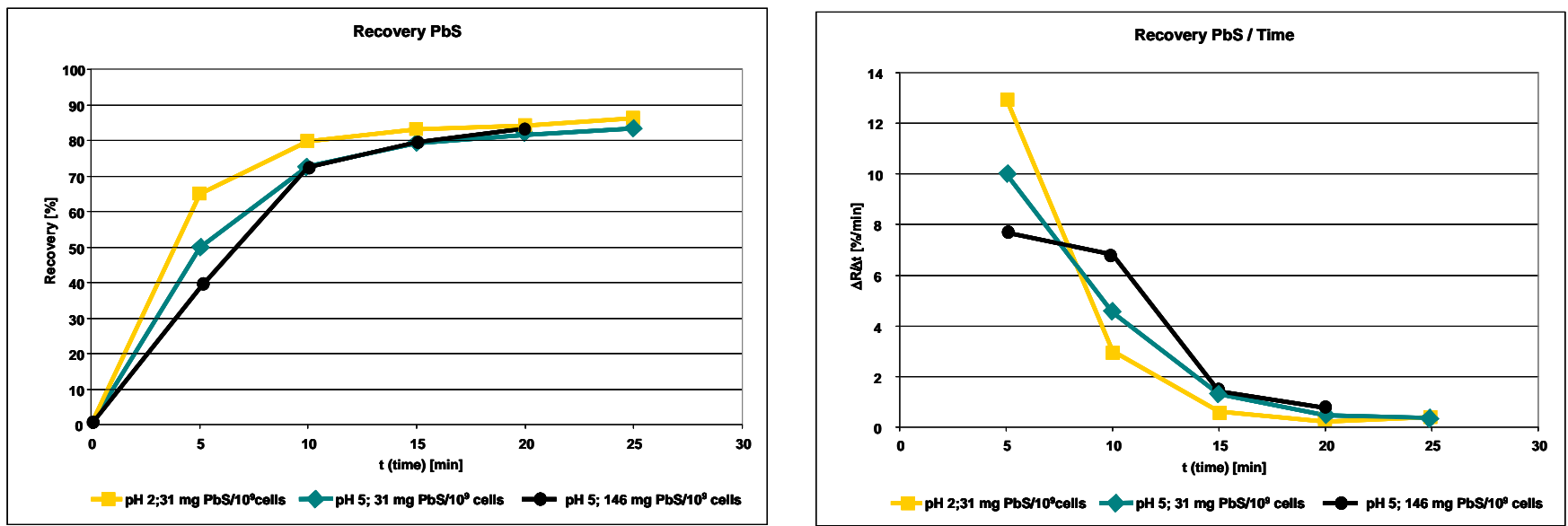

Fig. (13). Cumulative recovery $(\%)$ of $(\mathrm{PbS})$ (left) and flotation velocity $(\Delta \mathrm{R} / \Delta \mathrm{t}$, \%/min) (right) in batch tests with different $\mathrm{pH}$-values and varied ratios of mineral mass to cell concentration $\left(\mathrm{mg} / 10^{9}\right.$ cells).
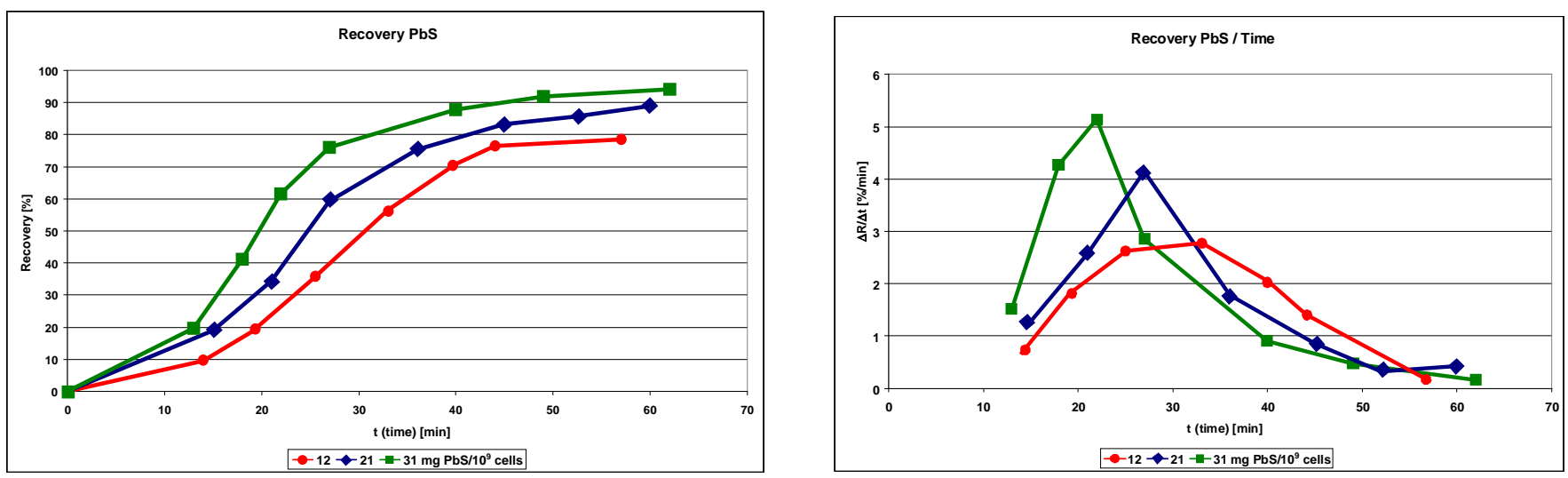

Fig. (14). Cumulative recovery $(\%)$ of $(\mathrm{PbS})($ left $)$ and flotation velocity $(\Delta \mathrm{R} / \Delta \mathrm{t}, \% / \mathrm{min})$ (right) in continuous tests with varied ratio of mineral mass to cell concentration $\left(\mathrm{mg} / 10^{9}\right.$ cells).

ters such as zeta-potential, particle radius, double layer thickness are known or measurable, while for calculation of Hamaker constant there are two different methods available. According to previous studies the macroscopic approach is more relevant.

In the presence of the mixture of different mineral particles the coagulation of the bacteria and mineral particles can be obtained selectively if the interaction energy level differs or can be influenced accordingly. The procedure of selective biocoagulation of microorganisms, e.g. yeasts like Saccharomyces cerevisiae and Yarrowia lipolytica, and micro-dispersed solids, e.g. minerals like galena, sphalerite and quartz, has been analysed with respect to selective biocoagulation. The characteristics of the cell surfaces of the microorganisms and minerals, e.g. the electrostatic charge, the composition of extracellular polymeric substances, the contact angle and the adhesion as well as their influence on the selective biocoagulation were studied.

The experimental investigations showed that the microorganisms and the sulphide particles below $10 \mu \mathrm{m}$ coagulate effectively. The experimental findings corroborate the theoretical analysis of the adhesion mechanism between sulphide particles and yeast cells and their selective coagulation. Furthermore it could be shown that flotation is suitable for the separation of the selectively formed biocoagulates. With the designed column flotation satisfying recovery rates are reached. Prospective research work will involve further steps for the optimisation of the process and scaling-up.

\section{ACKNOWLEDGEMENT}

The research work has been executed as a part of the Integrated EC Project "Biotechnology for Metal bearing materials in Europe (BioMinE)". The authors thank the European Commission for the financial support of the work.

\section{REFERENCES}

[1] F. Glombitza and H. Z. Kuyumcu, "Mikrobielles Sortieren", in 1. Kolloquium Sortieren, Innovationen und Anwendungen, 1999, pp. 141-149.

[2] W. Sand and E. R. Donati, Eds., Microbial processing of Metal sulphides. Dordrecht: Springer, 2007.

[3] M. Tsezos, "Biological removal of ions: Principles and applications", in Biohydrometallurgy: From the single cell to the environment, A. Schippers, W. Sand, F. Glombitza and S. Willscher, Eds., Stafa-Zurich: Trans Tech Publications Ltd., 2007, pp. 589-596.

[4] G. Rossi, Biohydrometallurgy. Hamburg, New York: McGrawHill, 1990.

[5] P. K. Sharma and K. H. Rao, "Adhesion of paenibacillus polymyxa on chalcopyrite and pyrite: surface thermodynamics and extended DLVO theory", Colloids and Surfaces B: Biointerfaces, vol. 29, pp. 21-38, 2003.

[6] D. R. Absolom, F. V. Lamberti, Z. Policova, W. Zingg, C. J. van Oss and A. W. Neumann, "Surface thermodynamics of bacterial adhesion", Applied and Environmental Microbiology, vol. 46, pp. 90-97, 1983. 
[7] H. J. Busscher, A. H. Weerkamp, H. C. van der Mei, A. W. van Pelt, H. P. de Jong and J. Arends, "Measurement of the surface free energy of bacterial cell surfaces and its relevance for adhesion", Applied and Environmental Microbiology, vol. 48, pp. 980-983, 1984.

[8] B. V. Deryagin and L. Landau, Acta Physicochem., URSS, vol. 55, pp. 333, 1941.

[9] E. J. Verwey and J. T. G. Overbeek, "Theory of the stability of lyophobic colloids", Journal of Colloid Science, vol. 10, pp. 224225,1955

[10] C. J. van Oss, R. J. Good and M. K. Chaudhury, "The role of van der Waals forces and hydrogen bonds in "hydrophobic interactions" between biopolymers and low energy surfaces", Journal of Colloids Surface B Biointerfaces Science, vol. 111, pp. 378-390, 1986.

[11] C. J. van Oss, M. K. Chaudhury and R. J. Good, "Monopolar surfaces”, Advvanced Colloid Interface Science, vol. 28, pp. 35-64, 1987.

[12] F. M. Fowkes, "Attractive forces at interfaces", Ind. Eng. Chem., vol. 56, pp. 40-52, 1964.

[13] A. Vilinska and K. Hanumantha Rao, "Surface thermodynamics and extended DLVO theory of Acidithiobacillus ferrooxidans cells adhesion on pyrite and chalcopyrite", The Open Colloid Science Journal, vol. 2, pp. 1-14, 2009.

[14] H. Z. Kuyumcu, J. Pinka, T. Bielig, "Investigations on the sorting of very fine particles by Biocoagulation", in Biohydrometallurgy: From single cell to the environment, A. Schippers, W. Sand, F. Glombitza and S. Willscher, Eds., Stafa-Zurich: Trans Tech Publications Ltd., 2007, pp. 337-340.

[15] A. Vilinska, K. Hanumantha Rao, and K. S. E. Forssberg, "Selective coagulation in chalcopyrite/pyrite mineral system using Acidothiobacillus group bacteria”, Advanced Maternal Research, vol. 20-21, pp. 366-370, 2007.

[16] J. H. Gary, I. L. Fled and E. G. Davis, "Chemical and physical beneficiation of Florida phosphate slimes", USBM RI 6163, pp. 3334, 1963.

[17] R. W. Smith, M. Misra and J. Dubel, "Mineral bioprocessing and the future", Minerals Engineerings, vol. 4, pp. 1127-1141, 1991.

[18] S. Long and F. Wagner, "Structure and properties of biosurfactants", in Biosurfactants and Biotechnology, N. Kosaric, W. L.
Cairns and N. C. C. Gray, Eds., New York: Marcel Dekker, 1987, pp. 21-46.

[19] C. E. Capes, A. E. McIllhinney, A. F. Sirianni and I. E. Puddington, "Bacterial oxidation in upgrading pyritic coals", Canadian Mineral and Metal Bulletin, vol. 66, pp. 88-91, 1973.

[20] R. J. Desphande, S. Subramanian and K. A. Natarajan, "Effect of bacterial interaction with Thiobacillus ferrooxidans on the floatability of phalerite and pyrite", in International Seminar on Mineral Processing Technology, 2001, pp. 159-161.

[21] K. Hanumantha Rao and P. K. Sharma, "Analysis of different approaches for evaluation of surface energy of microbial cells by contact angle goniometry", Advances. Colloid and Interface Science, vol. 98, pp. 341-463, 2002.

[22] M. N. Bellon-Fontaine, N. Mozes, H. C. van der Mei and O. Sjollema, "A comparison of Thermodynamic Approaches to predict the adhesion of dairy microorganisms to solid substrata", Cell Biophysics, vol. 17, pp. 93-106, 1990.

[23] G. Ström, M. Frederiksson and P. Stenius, "Contact angles, work of adhesion and interfacial tensions at a dissolving hydrocarbon surface", Journal of Colloid Interface Science, vol. 119, pp. 352361, 1987.

[24] P. B. Dengis and P. G. Rouxhet, "Surface properties of top- and bottom-fermenting yeast", Yeast, vol. 13, pp. 931-943, 1997.

[25] D. Q. Lin, P. J. Brixius, J. J. Hubbuch, J. Thommes and M. R. Kula, "Biomass/adsorbent electrostatic interactions in expanded bed adsorption: a zeta potential study", Biotechnology and Bioengineering, vol. 83, no. 2, pp. 149-157, 2003.

[26] J. Pinka, H. Z. Kuyumcu and F. Glombitza, "Untersuchungen zur Sortierung durch Biokoagulation“, in 4. Kolloquium Sortieren, Innovationen und Anwendungen, 2005, pp. 113-122.

[27] M. Aguedo, Y. Waché, J. M. Belin and J. A. Teixeira, "Surface properties of Yarrowia lipolytica and their relevance to $\gamma$.decalactone formation from methyl ricinoleate", Biotechnology Letters, vol. 27, pp. 417-422, 2005.

[28] H. Z. Kuyumcu, J. Pinka and T. Bielig, "A novel sorting process for fine-sized sulphide minerals using biocoagulation”, in International Workshop on Bioprocessing of Minerals, Changsha, China, 2008.

(C) Kuyumcu et al.; Licensee Bentham Open.

This is an open access article licensed under the terms of the Creative Commons Attribution Non-Commercial License (http://creativecommons.org/licenses/by$\mathrm{nc} / 3.0 /$ ) which permits unrestricted, non-commercial use, distribution and reproduction in any medium, provided the work is properly cited. 